\title{
Changes in quality of life following initial treatment of oesophageal carcinoma: a cohort study from Sri Lanka
}

\author{
Ishanka Ayeshwari Talagala ${ }^{{ }^{*}}$ (D) and Carukshi Arambepola ${ }^{2}$
}

\begin{abstract}
Background: Oesophageal carcinoma is one of the leading cancers in Sri Lanka. Recent advances in treatment modalities have drastically improved the survival of these patients. However, the quality of life (QoL) among the survivors needs to be reviewed in order to recognise the need for advocating more focussed rehabilitation for oesophageal carcinoma in Sri Lanka.

Methods: A prospective cohort study was conducted among 51 incident cases of oesophageal carcinoma recruited consecutively from the National Cancer Institute, Maharagama. Data were collected on their QoL using EORTC QLQ-C30 and EORTC-OES18 questionnaires validated for Sri Lankan oesophageal carcinoma patients, before and one month after the completion of initial treatment. Scoring was based on the EORTC manual. Comparison of baseline and follow-up scores was done using paired t test at significance level of 0.05 .

Results: Response rate was $80 \%$. The majority consisted of squamous cell carcinoma of stage IV. On a scale of 0-100, the overall QoL (mean score $=49.8 ; \mathrm{SD}=22)$; and role $(42.2 ; \mathrm{SD}=34)$, physical $(53.1 ; \mathrm{SD}=29)$, emotional $(53.4 ; \mathrm{SD}=26)$ and social $(57.2 ; \mathrm{SD}=23)$ functioning were relatively low at diagnosis. The scores of functioning scales further deteriorated (difference $>5$ points) following the initial treatment $(p<0.05)$. Dysphagia (mean $=54 ; \mathrm{SD}=27$ ) was the main symptom at diagnosis, which improved significantly $(p<0.05)$ in contrast to dry mouth (mean $=39.2$; SD $=34)$ that worsened $(p<0.05)$ following initial treatment. Family support and financial difficulties were adversely affected $(p<0.05)$ during the initial treatment.
\end{abstract}

Conclusions: The deterioration of several dimensions of QoL of oesophageal carcinoma patients following the initial treatment highlights the need for more targeted tertiary preventive strategies that address the issues identified.

Keywords: Quality of life, Oesophageal carcinoma, Tertiary prevention, Sri Lanka

\section{Background}

Oesophageal carcinoma plays a leading role in the global cancer burden $[1,2]$. It is identified as a virulent tumour particularly in the developing countries [3], thus imposing prompt action against it in these regions. Sri Lanka, a developing country in South Asia continuously reports oesophageal carcinoma as one of its five leading cancers [4]. According to the latest statistics available for Sri Lanka, $6.3 \%$ of all reported incident cancer cases were due to oesophageal carcinoma and it continues to be the

\footnotetext{
* Correspondence: drishanka@gmail.com

${ }^{1}$ National Programme for Prevention and Control of Non-Communicable Diseases, Ministry of Health Nutrition and Indigenous Medicine, Colombo, Sri Lanka

Full list of author information is available at the end of the article
}

third commonest cancer among males while being the sixth commonest among females [4].

Oesophageal carcinoma is known to be associated with poor prognosis, with five-year survival rates of $5-10 \%$ [5]. However, the recent advancements in treatment modalities of oesophageal carcinoma have drastically improved the survival of these patients within the last few decades around the world [6]. The situation is similar in Sri Lanka owing to the well-established free curative healthcare services in the country. Nevertheless, how improvement in survival has affected the quality of life (QoL) of the patients still remains inconclusive [7, 8].

Various treatment options available for oesophageal carcinoma may improve the survival, and thereby improve 
the QoL of the patients following the initial treatment. However, most patients (even with resectable oesophageal carcinoma) may have serious co-morbid conditions, thus the surgery would be poorly tolerated [9]; patients may also be affected by adverse effects following chemotherapy and radiotherapy [10]; troublesome symptoms such as dysphagia may recur [11], which all may affect the QoL of the patients with oesophageal carcinoma as a whole. Also, for some advanced stages of the disease, supportive care by means of palliation to improve their QoL, is essential [12].

The World Health Organization (WHO) defines QoL as "individuals' perception of their position in life in the context of the culture and value systems in which they live and in relation to their goals, expectations, standards and concerns" [13]. It is a broad concept that is affected in a complex manner by a person's physical health, psychological state, level of independence, social relationships, personal beliefs and their relationship to salient features of their environment [13]. In addition, medical parameters such as the mode of treatment, type of tumour and stage of disease [14], demographic variables [15] and the support extended by family members [16] have also shown to be important independent variables that affect the QoL of cancer patients.

Therefore, beyond survival from the disease, the important management end points would be the preservation, enhancement of patients' independence in activities of daily living and their satisfaction. Improving QoL in cancer patients has thus become an important therapeutic goal, and is also considered as an important outcome parameter. Currently, most treatment decisions are heavily influenced by their effect on the patients' QoL [17]. Therefore, a need arises to enhance the overall QoL of oesophageal cancer survivors through rehabilitation initiated at the time of diagnosis and continued until the terminal stage [18].

As in many other countries, the national policy for cancer prevention and control in Sri Lanka aims at a comprehensive programme [19], which includes the provision of palliative care services through universal health coverage. Even though many initiatives have been undertaken in this regard, further improvement of these services has been hampered due to the lack of evidence on the status (either improvement or deterioration) of the QoL of patients following the initial treatment. Bridging this knowledge gap on QoL aspects in the existing cancer management would enable targeted palliative care services as a tertiary preventive strategy in the country. Therefore, this study was aimed at assessing the change of QoL of the patients with oesophageal carcinoma following the initial treatment, irrespective of the treatment modality. Findings of this study would be helpful as evidence to improve cancer management programs of similar low resource settings as well.

\section{Methods}

A prospective cohort study was conducted during 2015-2016 period to compare the QoL of patients with oesophageal carcinoma, before and one month after the completion of initial treatment at the National Cancer Institute, Maharagama (NCIM). The NCIM is the only tertiary referral hospital situated in the Western province of Sri Lanka for cancer care. This state hospital is dedicated for free of charge in-ward and out-patient cancer care services including chemotherapy, radiotherapy and follow-up of cancer patients referred from both state and private sector hospitals. It caters mainly for the residents of Western province, which is the most populated province in Sri Lanka. Study participants were residents in the Western province, who were newly diagnosed with oesophageal carcinoma based on the histological confirmation following upper gastrointestinal endoscopy (UGIE) examination done within the last three months, and in whom the initial treatment (surgery, chemotherapy and/or radiotherapy) has not commenced by the date of recruitment into the study. Critically ill patients, patients with secondary carcinoma (e.g. metastasis) including oesophageal carcinoma, patients diagnosed with any other cancer (confirmed with documental evidence) and patients with relapses of any cancer including oesophageal carcinoma were excluded from the study.

Based on the available data for cancer incidence in Sri Lanka, Western province continuously reports very high incidence of Oesophageal carcinoma [20, 21]. Nevertheless, Western province being the most populated province of Sri Lanka, consists of the highest socio-economic diversity and include people from urban, rural and estate sectors, belonging to all social classes [22]. Therefore, findings of the quality of life of patients with oesophageal carcinoma is assumed not to differ much from the rest of the country. Thus, the current study was conducted in the Western province of Sri Lanka.

The sample size of the study was calculated with the aim of detecting clinically significant changes (either increase or decrease) in the QOL of patients with oesophageal carcinoma after the initial treatment. Thus, detecting at least a change between 5 and $10 \%$ in the QOL core questionnaire [23] was aimed at. This change is known to be noticed by the patients as a 'little' better or worse change and is regarded as the smallest clinically detectable significant change in QOL assessment [24].

Therefore, the calculated sample size of 51 was based on $5 \%$ significance level, beta error of 0.2 and $25 \%$ non-response rate, to detect at least a 'little' change in the QoL (mean difference $=3.2$; standard deviation $=$ 7.7) between pre-treatment and post-treatment scores [24] following the initial treatment among patients with oesophageal carcinoma. 
Following informed written consent, patients were consecutively recruited from the oncology and surgical wards and clinics, and were administered an interviewer-administered questionnaire to obtain data on socio-demographic characteristics. The QoL of participants was assessed using three questionnaires: EORTC QLQ-C30 core questionnaire and EORTC QLQ-OES18 module developed by the European Organization for Research and Treatment of Cancer (EORTC) - quality of life group [23], and another questionnaire on family support scale. Since the QLQ-C30 has been designed to assess only the generic aspects of QoL of patients with cancer, the QLQ-OES18 which is on the disease and treatment specific QoL of patients with oesophageal carcinoma was adopted to supplement the QLQ-C30 [25]. The family support scale was a locally developed questionnaire. All these questionnaires had been previously validated by Jayasekara (2006) for Sri Lankan adult patients with oesophageal carcinoma [8].

The EORTC QLQ-C30 (version 3.0) questionnaire incorporates nine multi-item scales: five functional scales (physical; cognitive; emotional; and social functioning); three symptom scales (fatigue; pain; and nausea and vomiting); and one scale on global health status/quality of life [26]. The EORTC QLQ-OES18 comprises four scale items (dysphagia; problems with eating; reflux; and pain) and six single items (trouble swallowing saliva; choked when swallowing; dry mouth; trouble with taste; trouble with coughing and trouble talking) [27]. The family support scale includes three items (whether the patient felt lonely; unhappy with the attention paid by the family; unhappy with the support extended by the family) [8].

The QoL of each patient in the cohort was assessed at two time points; initially at the time of diagnosis (base-line data) prior to their initial treatment, irrespective of the treatment plan. After obtaining their basic characteristics, the QLQ-C30 core questionnaire, family support scale and the QLQ-OES 18 were administered in sequence. The same cohort was then followed up to re-assess their QoL one month after completion of their initial treatment (follow-up data). Since the QoL of patients is well known to deteriorate during the acute phase of treatment due to its side effects [28, 29] and also soon after the initial treatment [8], it was decided to give a one month of treatment free period following the initial treatment, with the assumption that the side effects would wear off by then.

Data were analysed using the statistical package for the social sciences (SPSS) version 20. The scoring for the questionnaires were given based on the EORTC scoring manual, and all scale and single item scores were linearly transformed to a 0-100 scale [30]. Standardized skewness was calculated (to check whether it falls within
- 3.0 to 3.0) wherever necessary prior to the application of parametric analytical tests [31]. Scores of the follow-up study were compared with the baseline scores of QoL using paired t test at a significance level of 0.05 .

\section{Results}

The sample consisted of 51 newly diagnosed patients with oesophageal carcinoma, with ages ranging from 37 to 79 years. The mean age of the study participants was 60.2 $(\mathrm{SD}=11.2)$ years with the median being $60.0(\mathrm{IQR}=53.0$ 69.0) years. Majority of them were males (70.6\%). The basic characteristics of the patients are given in Table 1.

Majority of the patients were diagnosed with squamous cell carcinoma (63\%) and in advanced stage (56.2\%). Among the 14 patients who underwent surgery as their initial treatment modality for oesophageal carcinoma, $10(71.4 \%)$ underwent oesophagectomy while the rest (28.6\%) underwent stenting. Their clinical characteristics are compared with adenocarcinoma at the time of diagnosis (Table 2).

Of the 51 patients enrolled for follow up $(n=51), 10$ (19.6\%) died subsequently during the follow-up and therefore, the comparison of QoL scores between the baseline and follow-up was done among 41 patients. Among those who died, $50 \%$ were of more than 60 years in age; $90 \%$ were of low educational level (up to secondary level); $80 \%$ belonged to social class III, IV and V; and 80\% had metastasized disease. The average duration between baseline assessment of the QoL and the follow up assessment for the patients who underwent surgical treatment, radiotherapy, chemotherapy and neoadjuvant chemo-radiotherapy was 2.3 months ( $\mathrm{SD}=1.2) ; 3.8$ months $(\mathrm{SD}=2.3)$; 5.2 months $(\mathrm{SD}=2.8)$ and 4.2 months $(\mathrm{SD}=1.8)$ respectively. It should also be noted that the follow up assessment was done following a one month of treatment free period, after completing the initial treatment.

Table 3 shows the changes in the generic dimensions of QoL of patients before and after the initial treatment. The global health status/QoL of the patients has deteriorated between the baseline and follow-up following the initial treatment by 8.33 (SD = 30; 95\% CI: $-18.0,16.7)$. However, this difference was not significant (paired $t=1.8 ; \mathrm{df}=40$; $p=0.08)$. All functioning dimensions $(p<0.05)$ except cognitive functioning; and family support $(p=0.002)$ significantly deteriorated during the follow-up period. Among the general symptoms, fatigue; nausea and vomiting; pain; insomnia; loss of appetite; and constipation significantly worsened following the completion of initial treatment $(\mathrm{p}<0.05)$. In addition, financial difficulties significantly worsened during the follow-up $(p<0.001)$.

Changes in the disease-specific dimensions of QoL before and after the initial treatment are given in Table 4. Among the disease-specific symptoms, dysphagia significantly 
Table 1 Basic characteristics of the patients with oesophageal carcinoma

\begin{tabular}{|c|c|c|}
\hline Characteristic & $\begin{array}{l}\text { No. } \\
(N=51)\end{array}$ & $\%$ \\
\hline \multicolumn{3}{|l|}{ Sex } \\
\hline Male & 36 & 70 \\
\hline Female & 15 & 29. \\
\hline \multicolumn{3}{|l|}{ Age } \\
\hline $30-39$ & 2 & 3.9 \\
\hline $40-49$ & 7 & 13. \\
\hline $50-59$ & 15 & 29. \\
\hline $60-69$ & 16 & 31. \\
\hline $70-79$ & 11 & 21. \\
\hline \multicolumn{3}{|l|}{ Current civil status } \\
\hline Married & 43 & 84 \\
\hline Unmarried/widowed & 8 & 15. \\
\hline \multicolumn{3}{|l|}{ Highest educational qualifications } \\
\hline Primary and lower & 16 & 31. \\
\hline Secondary education & 34 & 66. \\
\hline Tertiary education & 1 & 2.0 \\
\hline \multicolumn{3}{|l|}{ Employment status } \\
\hline Currently employed & 31 & 60. \\
\hline Previously employed & 13 & 25 \\
\hline Never employed & 7 & 13. \\
\hline \multicolumn{3}{|l|}{ Social status ${ }^{a}$} \\
\hline Social class I - Leading professions & 1 & 2.0 \\
\hline Social class II - Lesser professions & 2 & 3.9 \\
\hline Social class III- Skilled workers and non-manual workers & 15 & 29. \\
\hline Social class IV - Partly skilled workers & 15 & 29. \\
\hline Social class V- Unskilled workers & 18 & 35. \\
\hline \multicolumn{3}{|l|}{ Monthly family income (USD) ${ }^{\mathrm{b}}$} \\
\hline$\leq 126$ & 25 & 49. \\
\hline $127-315$ & 21 & 41. \\
\hline $316-630$ & 5 & 9.8 \\
\hline
\end{tabular}

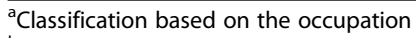

${ }^{\mathrm{b}} 1 \mathrm{USD}=$ LKR 158.73

improved following the initial treatment of oesophageal carcinoma (mean difference $=-13.6 ; \mathrm{SD}=29.7 ; p=0.006$ ); while dry mouth significantly worsened (mean difference $=20.3 ; \mathrm{SD}=39.4 ; p=0.002$ ). Improvement of trouble swallowing saliva and choking when swallowing, and the worsening of other symptoms following the initial treatment however were not statistically significant $(p>0.05)$.

\section{Discussion}

Our study, which aimed at assessing the changes in QoL of the patients with oesophageal carcinoma following the initial treatment, highlights that the generic as well
Table 2 Clinical characteristics of the patients with oesophageal carcinoma at the time of diagnosis

\begin{tabular}{|c|c|c|c|c|}
\hline \multirow[t]{2}{*}{ Characteristic } & \multicolumn{2}{|c|}{$\begin{array}{l}\text { Squamous } \\
\text { cell carcinoma } \\
(n=32)\end{array}$} & \multicolumn{2}{|c|}{$\begin{array}{l}\text { Adenocarcinoma } \\
(n=19)\end{array}$} \\
\hline & No. & $\%$ & No. & $\%$ \\
\hline \multicolumn{5}{|l|}{ Grade of the tumour } \\
\hline Well differentiated/G1 & 5 & 15.6 & 1 & 5.3 \\
\hline Moderately differentiated/ G2 & 21 & 65.6 & 12 & 63.2 \\
\hline Poorly differentiated/ G3 & 6 & 18.8 & 6 & 31.6 \\
\hline \multicolumn{5}{|l|}{ Stage of the tumour } \\
\hline Stage I & 0 & 0.0 & 1 & 5.3 \\
\hline Stage ॥ & 2 & 6.2 & 7 & 36.8 \\
\hline Stage III & 12 & 37.6 & 7 & 36.8 \\
\hline Stage IV & 18 & 56.2 & 4 & 21.1 \\
\hline \multicolumn{5}{|l|}{ Initial treatment undergone } \\
\hline Surgery & 6 & 18.8 & 8 & 42.1 \\
\hline Radiotherapy & 10 & 31.2 & 2 & 10.5 \\
\hline Chemotherapy & 4 & 12.5 & 5 & 26.3 \\
\hline Neo-adjuvant chemo-radiotherapy & 11 & 34.4 & 2 & 10.5 \\
\hline No treatment & 1 & 3.1 & 2 & 10.5 \\
\hline \multicolumn{5}{|l|}{ Time since first symptom to diagnosis } \\
\hline$\leq 3$ months & 20 & 62.5 & 13 & 68.5 \\
\hline$>3$ months & 12 & 37.5 & 6 & 31.5 \\
\hline \multicolumn{5}{|l|}{ Long standing co-morbid conditions } \\
\hline Yes & 2 & 6.3 & 3 & 15.8 \\
\hline No & 30 & 93.7 & 16 & 84.2 \\
\hline
\end{tabular}

as disease-specific dimensions of the QoL changes with time. In particular, the physical, role, emotional and social functioning, and general symptoms such as fatigue, nausea and vomiting, pain, insomnia, loss of appetite and constipation are significantly worsened during the follow-up. Among the disease-specific dimensions, dysphagia showed a significant improvement following the initial treatment in contrast to dry mouth. However, the deterioration of the overall global health status/QoL of the patients was found to be non-significant.

Quality of life is already considered an important indicator of the quality of cancer care, especially in developed countries, where most cancer treatment decisions are based not only on their effects on patient survival but also on the QoL [17]. Such decision making is not yet an integral component in the cancer management protocols in many developing countries, including Sri Lanka, mainly due to the lack of evidence on the QoL of patients with oesophageal carcinoma following treatment. Moreover, such evidence from developed countries may not be well applicable in the developing countries, given the 
Table 3 QOL scores for functioning and general symptoms dimensions of oesophageal carcinoma, before and after the initial treatment

\begin{tabular}{|c|c|c|c|c|c|c|c|c|}
\hline \multirow[t]{2}{*}{ Scale } & \multicolumn{2}{|l|}{ Baseline score } & \multicolumn{2}{|l|}{ Follow up score } & \multirow{2}{*}{$\begin{array}{l}\text { Mean } \\
\text { difference } \\
(N=41)\end{array}$} & \multirow[t]{2}{*}{ SD } & \multirow[t]{2}{*}{$95 \% \mathrm{Cl}$} & \multirow[t]{2}{*}{ Significance $^{e}$} \\
\hline & Mean $(N=51)$ & SD & Mean $(N=41)^{c}$ & SD & & & & \\
\hline Global health status/QOL & 49.8 & 22.0 & 43.9 & 30.4 & -8.33 & 30.0 & $-18.0,1.1$ & $\begin{array}{l}t=1.8 ; \mathrm{df}=40 \\
p=0.08\end{array}$ \\
\hline Physical functioning & 53.07 & 28.8 & 34.31 & 24.5 & -20.81 & 29.2 & $-30.03,-11.59$ & $\begin{array}{l}t=4.56 ; d f=40 \\
p<0.001\end{array}$ \\
\hline Role functioning & 42.16 & 34.5 & 21.54 & 26.2 & -22.76 & 37.8 & $-34.69,-10.84$ & $\begin{array}{l}t=3.86 ; d f=40 \\
p<0.001\end{array}$ \\
\hline Emotional functioning & 53.43 & 26.4 & 42.07 & 31.2 & -14.03 & 32.8 & $-24.38,-3.69$ & $\begin{array}{l}t=-2.74 ; \mathrm{df}=40 \\
p=0.009\end{array}$ \\
\hline Cognitive functioning & 75.49 & 23.4 & 71.54 & 26.9 & -6.1 & 26.0 & $-14.31,+2.12$ & $\begin{array}{l}t=1.5 ; \mathrm{df}=40 \\
p=0.141\end{array}$ \\
\hline Social functioning & 57.19 & 23.2 & 37.4 & 26.8 & -23.17 & 27.9 & $-31.96,-14.38$ & $\begin{array}{l}t=5.33 ; d f=40 \\
p<0.001\end{array}$ \\
\hline Family support ${ }^{a}$ & 82.57 & 20.4 & 80.49 & 14.4 & -6.5 & 12.9 & $-10.58,-2.43$ & $\begin{array}{l}t=3.23 ; \mathrm{df}=40 \\
p=0.002\end{array}$ \\
\hline Fatigue & 52.07 & 28.9 & 71.27 & 28.8 & 20.87 & 35.2 & $9.78,31.96$ & $\begin{array}{l}t=3.8 ; \mathrm{df}=40 \\
p<0.001\end{array}$ \\
\hline Nausea and vomiting & 40.2 & 34.4 & 54.07 & 37.6 & 13.0 & 39.0 & $0.7,25.31$ & $\begin{array}{l}t=2.14 ; \mathrm{df}=40 \\
p=0.039\end{array}$ \\
\hline Pain & 45.42 & 32.7 & 71.54 & 28.7 & 27.64 & 37.6 & $15.78,39.5$ & $\begin{array}{l}t=4.71 ; \mathrm{df}=40 \\
p<0.001\end{array}$ \\
\hline Dyspnoea & 24.18 & 26.7 & 27.64 & 29.7 & 5.69 & 30.6 & $-4.0,15.36$ & $\begin{array}{l}t=1.19 ; d f=40 \\
p=0.241\end{array}$ \\
\hline Insomnia & 33.33 & 32.0 & 43.9 & 35.3 & 13.82 & 36.5 & $2.3,25.34$ & $\begin{array}{l}t=2.43 ; d f=40 \\
p=0.02\end{array}$ \\
\hline Loss of appetite & 42.48 & 34.0 & 54.47 & 37.8 & 13.0 & 40.1 & $0.37,25.65$ & $\begin{array}{l}t=2.08 ; \mathrm{df}=40 \\
p=0.044\end{array}$ \\
\hline Constipation & 30.06 & 35.4 & 47.97 & 41.5 & 16.26 & 34.3 & $5.45,27.07$ & $\begin{array}{l}t=3.04 ; d f=40 \\
p=0.004\end{array}$ \\
\hline Diarrhoea & 10.46 & 18.2 & 4.88 & 14.1 & -5.69 & 21.0 & $-12.3,0.92$ & $\begin{array}{l}t=1.74 ; d f=40 \\
p=0.09\end{array}$ \\
\hline Financial difficulties $^{b}$ & 50.98 & 31.5 & 77.24 & 21.6 & 30.89 & 32.8 & $20.53,41.25$ & $\begin{array}{l}t=6.03 ; \mathrm{df}=40 \\
p<0.001\end{array}$ \\
\hline
\end{tabular}

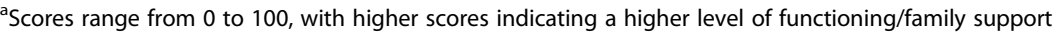

${ }^{b}$ Scores range from 0 to 100 , with higher scores indicating a higher degree of financial difficulties

'Ten patients died during the follow up period

${ }^{d}$ A negative mean difference indicates deterioration of functioning, family support and improvement of symptoms and a positive mean difference indicates worsening of symptoms and financial difficulties

epaired $t$ test

low resource settings and socio-cultural differentials in these countries.

An important finding of the current study is that the patients with oesophageal carcinoma have a low mean score for global health status $/$ QoL (mean score $=49.8$; $\mathrm{SD}=21.9)$ at the time of diagnosis. This finding is compatible with another study conducted in Sri Lanka (mean score $=47.9 ; \mathrm{SD}=22.8$ ) [8] and with the reference value given for baseline in the EORTC (mean score $=55.6$; $\mathrm{SD}=24.1$ ) [32]. Mental and physical burden of the patients following the disease process, diagnosis and social stigma associated with more culture-specific factors, could be the reasons following this low overall
QoL that persists from the time of diagnosis among the patients, irrespective of how advance the disease is. This situation is likely to have been worsened by the majority of patients being 60 years of age and above (53\%); of low educational level (67\% educated up to secondary level) and low social status (social class IV and V); with suffering from the symptoms of the disease for more than 3 months $(69 \%)$ and with metastatic disease (43\%).

The unpleasant acute adverse effects of cancer treatment, such as lethargy, alopecia, nausea and vomiting, mucositis and diarrhoea are known to be short-lived, which usually wear off by two-three weeks following therapy [33]. This justifies the assessment of QoL after 
Table 4 QOL scores for disease specific dimensions of oesophageal carcinoma, before and after the initial treatment

\begin{tabular}{|c|c|c|c|c|c|c|c|c|}
\hline \multirow{2}{*}{$\begin{array}{l}\text { Disease-specific } \\
\text { dimension }^{\mathrm{a}}\end{array}$} & \multicolumn{2}{|l|}{ Baseline score } & \multicolumn{2}{|l|}{ Follow up score } & \multirow{2}{*}{$\begin{array}{l}\text { Mean } \\
\text { difference } \\
(N=41)\end{array}$} & \multirow[t]{2}{*}{ SD } & \multirow[t]{2}{*}{$95 \% \mathrm{Cl}$} & \multirow[t]{2}{*}{ Significance $^{d}$} \\
\hline & Mean $(N=51)$ & SD & Mean $(N=41)^{b}$ & SD & & & & \\
\hline Dysphagia & 54.03 & 27.0 & 37.13 & 29.0 & -13.55 & 29.7 & $-22.91,-4.19$ & $\begin{array}{l}t=2.93 ; \mathrm{df}=40 \\
p=0.006\end{array}$ \\
\hline Problems with eating & 31.21 & 22.0 & 30.28 & 23.1 & 1.63 & 27.3 & $-7.0,10.25$ & $\begin{array}{l}t=0.38 ; d f=40 \\
p=0.705\end{array}$ \\
\hline Reflux & 42.48 & 29.5 & 44.97 & 36.4 & 7.32 & 36.9 & $-4.33,18.97$ & $\begin{array}{l}t=1.27 ; d f=40 \\
p=0.212\end{array}$ \\
\hline Pain & 29.63 & 25.7 & 30.08 & 32.3 & 3.25 & 32.8 & $-7.1,13.6$ & $\begin{array}{l}t=0.64 ; \mathrm{df}=40 \\
p=0.529\end{array}$ \\
\hline Trouble swallowing saliva & 24.84 & 35.2 & 22.76 & 32.9 & -2.44 & 34.5 & $-13.32,8.44$ & $\begin{array}{l}t=0.45 ; \mathrm{df}=40 \\
p=0.653\end{array}$ \\
\hline Choked when swallowing & 22.88 & 30.2 & 18.7 & 26.9 & -1.63 & 30.7 & $-11.31,8.06$ & $\begin{array}{l}t=0.34 ; \mathrm{df}=40 \\
p=0.736\end{array}$ \\
\hline Dry mouth & 39.22 & 34.4 & 58.54 & 37.1 & 20.33 & 39.4 & $7.9,32.74$ & $\begin{array}{l}t=3.31 ; \mathrm{df}=40 \\
p=0.002\end{array}$ \\
\hline Trouble with taste & 25.49 & 32.4 & 37.4 & 35.1 & 13.0 & 46.5 & $-1.66,27.68$ & $\begin{array}{l}t=1.79 ; \mathrm{df}-40 \\
p=0.081\end{array}$ \\
\hline Trouble with coughing & 37.25 & 32.4 & 42.28 & 39.5 & 7.32 & 36.9 & $-4.33,18.96$ & $\begin{array}{l}t=1.27 ; \mathrm{df}=40 \\
p=0.212\end{array}$ \\
\hline Trouble talking & 32.68 & 31.6 & 28.46 & 33.8 & 0.0 & 41.5 & $-13.1,13.1$ & $\begin{array}{l}t=0.0 ; \mathrm{df}=40 \\
p=1.00\end{array}$ \\
\hline
\end{tabular}

${ }^{a}$ Scores range from 0 to 100 , with higher scores indicating a higher degree of symptoms

${ }^{\mathrm{b}}$ Ten patients died during the follow up period

${ }^{\mathrm{C}} \mathrm{A}$ positive mean difference indicates worsening of symptoms and negative mean difference indicates improvement of symptoms

${ }^{d}$ paired t test

one month treatment free period in the current study, so that such acute effects were minimal on their QoL [33]. Nevertheless, the present study shows that the global health status, the functioning dimensions of the QoL and the general symptoms of cancer deteriorate from the baseline, indicating that there are many factors other than the stage of the disease [12] and the treatment modality, that affect the QoL of patients with oesophageal carcinoma. Therefore, findings seen on the change in QoL following the initial treatment may not truly reflect the sole effect of the treatment modality on the QoL of the patients in Sri Lanka. Thus, other potential influencing factors need to be further explored preferably using qualitative research methods.

The current study importantly points out a significant improvement in dysphagia, the major symptom related to oesophageal carcinoma, following the initial treatment. However, dry mouth, loss of appetite and nausea and vomiting were significantly worsened during the follow up. Though not statistically significant, trouble with taste also was worsened during the follow up. All these factors may have collectively resulted in the worsening of problems with eating among the patients with oesophageal carcinoma, although dysphagia was significantly improved following the initial treatment. Oesophageal carcinoma is a common disease to lose weight due to its disease process. The anthropometry measurements in the current study were taken at the time of recruitment of the patients to the study, after the onset of the disease, by which time a higher proportion of patients had lost their weight. Therefore, interpreting the findings of the study utilizing the current weight of the pateints will not portray the correct improvement or deterioration of body weight following the increased or decreased ability to consume meals by the patients after the initial treatment. Thus, the authors did not include the body weight in the manuscript.

Pain, fatigue and insomnia are also not alleviated by the initial treatment modalities. Though not statistically significant, many other disease specific symptoms were worsened during the follow-up as well. This suggests the need of incorporating therapeutic interventions into the rehabilitation program of the country to counter act these. However, Jayasekara (2006) cites that the interpretation of the results on reflux has to be done cautiously as there are existing doubts regarding the ability of the scale to measure this aspect [8]. Also, there are doubts whether reflux is a co-morbidity or a consequence of the oesophageal carcinoma and its treatments [8].

In the present study, significant deterioration of the physical, role, emotional and social functioning was seen after completion of the initial treatment, which was comparable with another study conducted in Sri Lanka 
[8]. However, the current study failed to detect a significant change in the cognitive functions following the treatment. In contrast, Jayasekara (2006) found a marginal improvement in the cognitive functioning from the baseline. He further reported that based on the validation results of QLQ-C30 to Sri Lankan oesophageal carcinoma patients; there is a further need to incorporate additional items to cover several aspects of cognitive functioning in the original questionnaire [8]. Thus, the interpretation of cognitive functioning scale scores has to be done cautiously.

Another noteworthy finding of this study is the significant worsening of financial difficulties between the baseline and the follow-up, reflecting the impact of the disease and treatment on the economical aspect of the patient. Even though higher baseline mean score was obtained for the family support reflecting the support extended by the family during the illness, this significantly deteriorated during the follow-up. Given the low health spending of $2 \%$ Gross Domestic Product in 2014 [34], cancer care in Sri Lanka is being increasingly financed by out-of-pocket expenditure [35]. This financial burden incurred on the family who are the care givers of the patients could have resulted in the deterioration of family support with time. Additional costs on adopting newer technologies in their treatment would have worsened this matter. This implicates the importance of harnessing social support and protection, and financial protection for the patients as integral parts of universal health coverage, especially in developing countries like Sri Lanka.

In summary, the significant reduction observed in the functioning of patients resulting in low level of independence; worsening of debilitating symptoms such as fatigue, pain, insomnia, loss of appetite, nausea/vomiting, dry mouth, trouble coughing, reflux and problems with eating; no improvement in trouble with talking resulting in social isolation; worsening of financial difficulties and reduction of family support, all would have a cumulative effect on the QoL of patients with oesophageal carcinoma. Therefore, all these findings should be taken into consideration when planning and implementing palliative care activities for patients with oesophageal carcinoma in Sri Lanka.

\section{Strengths and limitations}

The current study included patients of varying educational status. Therefore, even if the questionnaires used had been validated as self-administered ones, these were administered by interviewers in the present study. This could have resulted in over or under estimation of this assessment.

The current study was conducted in the Western province of Sri Lanka. Since the NCIM is the only tertiary care referral hospital for cancer care in the Western province dedicated to provide free of charge cancer management services, oesophageal carcinoma patients diagnosed both from other state and private sector hospitals are referred to NCIM for further management. Thus, the current study sample is well representative of the oesophageal cancer patients in the Western province. However, authors are aware that one may argue with the generalizability of the current study findings to oesophageal cancer patients in Sri Lanka. Western province has continuously reported high incidence of oesophageal carcinoma. Also, it is the most populated province of Sri Lanka and consists of the highest socioeconomic diversity and include people from urban, rural and estate sectors, belonging to all social classes. Therefore, findings of the quality of life of patients with oesophageal carcinoma is assumed not to differ much from the rest of the country. Nevertheless, there is a possibility that the QoL of oesophageal carcinoma patients from rural areas of Sri Lanka be worse than that is presented in the current study.

The objective of the current study was to assess the QoL of patients with oesophageal carcinoma following the initial treatment, irrespective of the treatment modality. Therefore, a detailed analysis of how much the QoL varies specific to a certain treatment modality was not assessed.

\section{Conclusions}

The QoL of patients with oesophageal carcinoma was shown to be multi-dimensional. Further deterioration seen of physical, role, emotional and social functioning; general and disease-specific symptoms following the initial treatment emphasizes the need for incorporating treatment and management options in the rehabilitation program. Worsening financial difficulties and the decline in family support reveal the need for counselling of patients and their family members, and the importance of financial protection of patients, as an integral part of the universal coverage of services to cancer patients in Sri Lanka. These findings emphasise the importance of the implementation of community based rehabilitation programmes through palliative care approach by the state for the tertiary prevention of oesophageal carcinoma by improving the QoL of patients with oesophageal carcinoma.

\section{Abbreviations \\ DALY: Disability Adjusted Life Years; EORTC: European Organization for Research and Treatment of Cancer; NCIM: National Cancer Institute Maharagama; QoL: Quality of life; SPSS: Statistical Package for the Social Sciences; UGIE: Upper gastrointestinal Endoscopy; WHO: World Health Organization}

\section{Acknowledgements}

Authors acknowledge the support extended by the family members of all the study participants. 


\section{Funding}

The research was partly funded by the Medical Research Institute, Colombo, Sri Lanka. The funding body did not have any direct role in the design of the study, analysis, interpretation of data and in writing the manuscript.

\section{Availability of data and materials}

Data will not be shared as prior permission to share data was not obtained.

\section{Authors' contributions}

IA was the principal investigator of the study. IA and CA have made substantial contributions to the conception, design and interpretation of the data. IA collected and analysed the data. IA and CA drafted the manuscript and critically analysed for its intellectual content. IA and CA agree to be accountable for all aspects of the work in ensuring that questions related to the accuracy or integrity of any part of the work are appropriately investigated and resolved. Both authors have read and approved the final manuscript.

\section{Authors' information}

IA is specialist in Community Medicine, has Masters degree and Doctorate of Medicine in Community Medicine and is attached to the National Programme for the prevention and control of Non-Communicable Diseases, Ministry of Health, Nutrition and Indigenous Medicine, Sri Lanka.CA is a Professor in Community Medicine, has Masters Degree and Doctorate of Medicine in Community Medicine, attached to the Department of Community Medicine, Faculty of Medicine, University of Colombo, Sri Lanka.

\section{Ethics approval and consent to participate}

Ethics clearance was obtained from the ethics review committee of the Faculty of Medicine, University of Colombo, Sri Lanka. Administrative clearance was obtained from the Director and the relevant Specialists of the NCIM. Written informed consent was obtained from all the eligible participants of the study.

\section{Consent for publication}

Not applicable.

\section{Competing interests}

The authors declare that they have no financial and non-financial competing interests.

\section{Publisher's Note}

Springer Nature remains neutral with regard to jurisdictional claims in published maps and institutional affiliations.

\section{Author details}

${ }^{1}$ National Programme for Prevention and Control of Non-Communicable Diseases, Ministry of Health Nutrition and Indigenous Medicine, Colombo, Sri Lanka. ${ }^{2}$ Department of Community Medicine, Faculty of Medicine, University of Colombo, Colombo, Sri Lanka.

Received: 14 February 2018 Accepted: 19 November 2018

Published online: 29 November 2018

\section{References}

1. GLOBOCAN. Estimated cancer incidence, mortality and prevalence worldwide in 2012. In: Fact sheets; 2012

2. Ling TC, Kang Jl, Slater JD, Yang GY. Proton therapy for gastrointestinal cancers. Translational cancer research. 2012;1:3.

3. Di Pardo BJ, Bronson NW, Diggs BS, Thomas CR Jr, Hunter JG, Dolan JP. The global burden of esophageal Cancer: a disability-adjusted life-year approach. World J Surg. 2015.

4. National Cancer Control Programme. Cancer Incidence Data: Sri Lanka, 2010. In: Programme NCC. Colombo, editor. Cancer Incidence Data. Sri Lanka: National Cancer Control Programme; 2016.

5. Marmot M, Atinmo T, Byers T, Chen J, Hirohata T, Jackson A, James W, Kolonel L, Kumanyika S, Leitzmann C, et al. Food, Nutrition,Physical activity and the prevention of Cancer: a global perspective: World Cancer Research Fund/American institute for. Cancer Res. 2007.

6. Law S, Kwong DLM, Kwok K-F, Wong K-H, Chu K-M, Sham JST, Wong J. Improvement in treatment results and long-term survival of patients with esophageal Cancer: impact of Chemoradiation and change in treatment strategy. Ann Surg. 2003;238(3):339-48.

7. Yajuan LV, Zhang J, Qiao L. Quality of life in patients with esophageal cancer receiving definitive chemoradiotherapy or esophagectomy. Molecular and Clinical Oncology. 2014;2(5):870-4.

8. Jayasekara H. An assessment of quality-of-life and satisfaction with care in patients diagnosed with some common cancers. In: Post graduate Institute of Medicine, University of Colombo; 2006.

9. Enzinger PC, Mayer RJ, Cancer E. N Engl J Med. 2003;349:2241-52.

10. Henriksson R, Bergström P, Franzén L, Lewin F, Wagenius G. Aspects on reducing gastrointestinal adverse effects associated with radiotherapy. Acta Ancologica. 1999;38(2):159-64.

11. SIGN. Management of oesophageal and Gastric Cancer: A national clinical guideline. In: Edinburgh Scottish Intercollegiate Guidelines Network (SIGN); 2006.

12. Treating Esophagus cancer. https://www.cancer.org/cancer/esophaguscancer/treating/by-stage.html.

13. WHO. WHOQOL - Measuring quality of life. In: World Health Organization; 1997.

14. Ravasco P, Monteiro-Grillo I, Vidal PM, Camilo ME. Cancer: disease and nutritionare key determinants of patients' quality of life. Support Care Cancer. 2004;12:246-52.

15. De Haes JCJM, Van Knippenberg FCE, Neijt JP. Measuring psychological and physical distress in cancer patients: Structure and application of the Rotterdam Symptom Checklist. British Journal of Cancer. 1990;62:1034-8.

16. Abdollahzadeh F, Aghahossini SS, Rahmani A, Kermani IA. Quality of life in Cancer patients and its related factors. J Caring Sci. 2012;1(2):109-14.

17. Soni MK, Cella D. Quality of life and symptom measures in oncology: an overview. Am J Manag Care. 2002;8(18 Suppl):S560-73.

18. Okamura H. Importance of rehabilitation in Cancer treatment and palliative medicine. Jpn J Clin Oncol. 2011;41(6):733-8.

19. Ministry of Health Nutrition \& Indigenous medicine- Sri Lanka. National Policy and strategic framework on Cancer Prevention \& Control. Colombo: Ministry of Health, Nutrition \& Indigenous Medicine; 2015.

20. National Cancer Control programme. Cancer Incidence Data: Sri Lanka, 2008. In: programme Ncc, editor. Cancer Incidence Data. Colombo: National Cancer Control Programme; 2014.

21. National Cancer Control programme.: Cancer incidence data Sri Lanka 2010 In: Cancer incidence data Sri Lanka. Edited by National Cancer Control Programme. Colombo: National Cancer Control Programme. 2016.

22. Department of Census and Statistics. In: DoCaS SL, editor. Census of population and housing, Sri Lanka-2012. Sri Lanka: Department of Census and Statistics; 2012

23. Osoba D, Rodrigues G, Myles J, Zee B, Pater J. Interpreting the significance of changes in health-related quality-of-life scores. J Clin Oncol. 1998; 16(1):139-44

24. Young $T$, de Haes $H$, Curran D, Fayers P, Brandberg Y, Vanvoorden V, Bottomley A. on behalf of the EORTC Quality of Life Group and QOL unit. In: Guidelines for assessing quality of life in EORTC clinical trials (version 2). EORTC: Brussels; 2002.

25. Blazeby JM, Williams MH, Brookes ST, Alderson D, Farndon JR. Quality of life measurement in patients with oesophageal cancer. Gut. 1995:37:505-8.

26. Aaronson NK, Ahmedzai S, Bergman B, Bullinger M, Cull A, Duez NJ, Filberti A, Flechtner H, Fleishman SB, De Haes J, et al. The European Organization for Research and Treatment of Cancer QLQ-C30: a quality of life instrument for use in international clinical trials in oncology. J Natl Cancer Inst. 1993; 85(5):365-76.

27. Blazeby JM, Conroy T, Hammerlid E, Fayers P, Sezer O, Koller M, Arraras J, Bottomley A, Vickery CW, Etienne PL, et al. Clinical and psychometric validation of an EORTC questionnaire module, the EORTC QLQ-OES18, to assess quality of life in patients with oesophageal cancer. Eur J Cancer. 2003;39(10):1384-94.

28. Kelly C, Paleri V, Downs C, Shah R. Deterioration in quality of life and depressive symptoms during radiation therapy for head and neck cancer. Otolaryngology- Head and neck surgery. 2007;136(1):108-11.

29. Hauser C, Patett C, Von Schoenfels W, Heits N, Schafmayer C, Malchow B, Hampe J, Schniewind B, Becker T, Egberts JH. Does neoadjuvant treatment before oncologic esophagectomy affect the postoperative quality of life? A prospective, longitudinal outcome study. Diseases of the esophagus. 2014; (Epub ahead of print).

30. Fayers PM, Aaronson NK, Bjordal K, Groenvold M, Curran D, Bottomley A. On behalf of the EORTC quality of life group: the EORTC QLQ-C30 scoring 
manual (3rd edition). Brussels: European organisation for research and treatment of. Cancer. 2001.

31. Hippel PV. Skewness. In: International encyclopedia of statistical science. New York: Springer; 2010.

32. Scott NW, Fayers PM, Aaronson NK, Bottomley A, Graeff A, Groenvold M, Gundy C, Koller M, Petersen MA. Sprangers MAG: on behalf of the EORTC Quality of Life Group. In: EORTC QLQ-C30 Reference Values. EORTC: Brussels; 2008.

33. Gore M, Russell D. Cancer in primary care. Taylor and Francis Group plc: London, United Kingdom; 2003.

34. World Bank: Health expenditure, public (\% of GDP). In: Data. The World Bank; 2016.

35. World Bank: Tackling Non-Communicable Diseases in Sri Lanka. In.; 2011.

Ready to submit your research? Choose BMC and benefit from:

- fast, convenient online submission

- thorough peer review by experienced researchers in your field

- rapid publication on acceptance

- support for research data, including large and complex data types

- gold Open Access which fosters wider collaboration and increased citations

- maximum visibility for your research: over $100 \mathrm{M}$ website views per year

At BMC, research is always in progress.

Learn more biomedcentral.com/submissions 